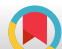

\title{
Synergistic Effects of Metformin-Lapatinib Combination on the Expression of Bax in SK-BR3 Cells
}

\author{
Bahman Moradipoodeh ${ }^{1}$, Ghorban Mohammadzadeh ${ }^{2}$, Davood Neamati ${ }^{1}$, Mahdieh Koushki ${ }^{1}$, \\ Rahim Moradi ${ }^{1}$, Anise Kiashi ${ }^{3}$ and Fatemeh Ahmadpour (iD) ${ }^{4, *}$ \\ ${ }^{1}$ Department of Biochemistry, Faculty of Medicine, Ahvaz Jundishapur University of Medical Science, Ahvaz, Iran \\ ${ }^{2}$ Department of Clinical Biochemistry, Hyperlipidemia Research Center, Faculty of Medicine, Ahvaz Jundishapur University of Medical Sciences, Ahvaz, Iran \\ ${ }^{3}$ Ahvaz Golestan Hospital, Faculty of Medicine, Ahvaz Jundishapur University of Medical Sciences, Ahvaz, Iran \\ ${ }^{4}$ Student Research Committee, Department of Biochemistry, Faculty of Medicine, Ahvaz Jundishapur University of Medical Science, Ahvaz, Iran \\ "Corresponding author: Student Research Committee, Department of Biochemistry, Faculty of Medicine, Ahvaz Jundishapur University of Medical Science, Ahvaz, Iran. Email: \\ ahmadpourfatimaa@gmail.com
}

Received 2020 November 03; Revised 2020 December 02; Accepted 2020 December 05.

\section{Abstract}

Background: HER2-positive breast cancers tend to be more aggressive and are associated with poorer outcomes than other types of breast cancer. Metformin, the first-line medication for the treatment of type 2 diabetes, has anticancer activity against various cancerous cells.

Objectives: We assessed the cytotoxic effect of metformin in combination with Lapatinib on the SK-BR3 cells.

Methods: Following culturing cells, $\mathrm{IC}_{50}$ of metformin and lapatinib were calculated using MTT assay after $48 \mathrm{~h}$ of treatment with different concentrations of metformin and lapatinib alone and in combination. The level of pro-apoptotic protein Bax expression was measured by western blot analysis.

Results: Metformin and lapatinib could significantly inhibit the cell viability of SKBR-3 in a dose-dependent manner, and the minimum cytotoxic effect of these drugs was observed after $48 \mathrm{~h}$ at $5 \mathrm{mM}$ and $50 \mathrm{nM}$, respectively. Several combinations of metformin with lapatinib showed a synergistic efficacy on the cell viability inhibition, which could decrease the $\mathrm{IC}_{50}$ of lapatinib from $500 \mathrm{nM}$ to at least $200 \mathrm{nM}$. The strongest synergistic cytotoxic effect on the cell viability was observed at $40 \mathrm{mM}$ of metformin plus $400 \mathrm{nM}$ of lapatinib. Furthermore, after $48 \mathrm{~h}$ of co-treatment with metformin-lapatinib combination, the level of pro-apoptotic Bax expression was significantly increased at $10 \mathrm{mM}$ of metformin plus $200 \mathrm{nM}$ of lapatinib.

Conclusions: This study demonstrated that the metformin-lapatinib combination may be a valuable candidate for breast cancer patients with HER2 overexpression. However, further studies are needed to make a definitive conclusion.

Keywords: Lapatinib, Metformin, Breast Cancer, Bax, SK-BR3 Cell Line

\section{Background}

Breast cancer, a type of malignancy that originated from breast tissue, is the leading type of cancer in women and the second leading cause of cancer-related deaths in women worldwide $(1,2)$. Breast cancer patients with overexpression of human epidermal growth factor receptor type 2 (HER2) commonly have low rates of disease-free survival, resistance to chemotherapy and hormone treatment, and high metastasis and mortality (3). Approximately in $20-30 \%$ of breast cancer patients, the HER2 is overexpressed $(4,5)$. Most chemical therapeutics is based on inducing apoptotic death to reduce the proliferation of cancerous cells (6). One of the common features of cancerous cells is to engage different mechanisms to escape apoptosis. Bcl-2 family proteins are highly involved in the intrin- sic apoptosis pathway that is often triggered in response to chemotherapeutic agents $(7,8)$. The Bcl-2 family proteins like Bax and Bcl-2 have pro-apoptotic and anti-apoptotic activities, respectively.

Lapatinib is an orally anti-proliferative drug that is used for the treatment of breast cancer and other solid tumors. It is a dual tyrosine kinase inhibitor of HER2 kinases and epidermal growth factor receptor (EGFR) (9, 10). Lapatinib inhibits activation of HER2 and can suppress their major downstream signaling proteins such as Akt and extracellular signal-regulated kinases (ERKs) 1/2 $(11,12)$. Some studies reported that lapatinib can inhibit cell proliferation and promote apoptotic death by downregulating Bcl2 and up-regulation of Bax, cleaved caspase3 , and cleaved caspase-9 expression (13). Unfortunately, pri- 
mary or acquired resistance to lapatinib and multiple offtarget side effects still occurs when treating breast cancer (14).

Metformin is the first-line medication for type 2 diabetes (15). Some studies have argued that metformin may prevent the proliferation of cancer cells (16). For breast cancer patients, metformin can decrease breast cancer cell viability via increasing the level of reactive oxygen species $(\mathrm{ROS})(17,18)$. Since the effects of lapatinib and metformin on cell viability and apoptotic death have been investigated in some studies $(19,20)$.

\section{Objectives}

The current study aimed to investigate the cytotoxic effects of metformin in combination with lapatinib on the cell viability and expression of Bax in the SKBR3 human breast cancer cell line as a HER2 overexpress cell line.

\section{Methods}

\subsection{Cell Culture and Cell Viability Determination}

The SK-BR3 cells were obtained from the Pasteur Institute of Iran (Tehran, Iran). The cells were cultured in DMEM containing 10\% fetal bovine serum (FBS) and $0.5 \%$ pen-strep at $37^{\circ} \mathrm{C}$. Approximately $5 \times 10^{3}$ cells were seeded in 96-well plates and allowed to receive $70 \%$ confluence. To assess the cytotoxic effect of metformin and lapatinib, the cells were treated with different concentrations of metformin (5-80 mM) and lapatinib (50-600 $\mathrm{nM}$ ) alone and in combination for 48 hours, following the principles followed by previous studies $(21,22)$. The cells of the control group were left untreated. Therefore, four groups, including untreated, treated with lapatinib, treated with metformin, and treated with the lapatinib-metformin combination, were assessed in the current study. After 48 hours, $20 \mu \mathrm{l}$ of MTT (3-(4,5-dimethilthiazol-2yl)-2,5-diphenyl tetrazolium bromide) Sigma- Aldrich (St. Louis, MO, USA) solution $(1 \mathrm{mg} / \mathrm{ml})$ was added and incubated at $37^{\circ} \mathrm{C}$ for $4 \mathrm{~h}$. After solubilizing the blue formazan crystal in $100 \mu \mathrm{l}$ DMSO at $37^{\circ} \mathrm{C}$ for $30 \mathrm{~min}$, the absorbance was measured at $570 \mathrm{~nm}$ using BioTek ELX800 microplate reader (Winooski, United States). The percentage of viable cells was calculated as:

(O.D. of drug-treated sample/control O.D.) $\times 100$.

This project was approved by the Ethics Committee at Ahvaz Jundishapur University of Medical Sciences, Ahvaz, Iran (IR.AJUMS.REC.1397.916).

\subsection{Western Blotting}

The gathered cells were lysed with the cold RIPA buffer containing $1 \%$ protease inhibitor cocktail (Thermo, Rockford, IL) for $20 \mathrm{~min}$. Then, all cells were centrifuged at $12000 \mathrm{rpm}$ for $15 \mathrm{~min}$ at $4^{\circ} \mathrm{C}$. The total protein content of the lysates was determined using a BCA protein quantification kit. The protein samples (60 $\mu \mathrm{g}$ ) were electrophoresed on a $12 \%$ polyacrylamide gel (SDS-PAGE) and then transferred to the PVDF membrane. Afterward, the membranes were blocked with $5 \%$ skim milk for $1 \mathrm{~h}$, probed with primary anti-Bax antibody (Abcam Inc, Cambridge, UK, ab32503, 1:1000 dilution) and anti-Beta-actin as internal control (Cell Signaling Technology, Danvers, MA, USA, $4970 \mathrm{~L}, 1: 2000$ dilution) antibodies overnight at $4^{\circ} \mathrm{C}$. Then, the membranes were incubated with the secondary goat anti-rabbit antibody (Cell Signaling Technology, Danvers, MA, USA, 7074s, 1:10000 dilution) for $1 \mathrm{~h}$ at room temperature. Finally, the membranes were incubated with ECL detection reagent to visualize the protein band by Bio-Rad ChemiDocTM (Hercules, CA, USA).

\subsection{Statistical Analysis}

Statistical analyses were performed using SPSS. Data are expressed as mean \pm standard error of the mean (S.E.M) for three independent experiments. The comparisons of mean variables between groups were performed using the One-way ANOVA followed by the Tukey post hoc test.

\section{Results}

4.1. Cytotoxic Effect of Lapatinib and Metformin on the SKBR-3 Cells

The inhibitory effect of lapatinib on the cell viability was assessed, and the least cytotoxicity was observed after $48 \mathrm{~h}$ of treatment at $50 \mathrm{nM}$. The dose-dependent inhibitory effect of lapatinib on cell viability was evaluated based on its $\mathrm{IC}_{50}$. The results are briefly provided in Figure 1 . After 48 $\mathrm{h}$ of treatment with lapatinib, the value of $\mathrm{IC}_{50}$ on the cell viability was estimated at approximately $250 \mathrm{nM}$ (Figure 1). The inhibitory effect of metformin on the cell viability was assessed, and its least cytotoxicity was observed after $48 \mathrm{~h}$ of treatment at $5 \mathrm{mM}$. The dose-dependent inhibitory effect of metformin on the cell viability was evaluated based on its $\mathrm{IC}_{50}$ and the results are briefly provided in Figure 2. After $48 \mathrm{~h}$ of treatment with metformin, the value of IC $_{50}$ on the cell viability was estimated at approximately $40 \mathrm{mM}$ (Figure 2). 


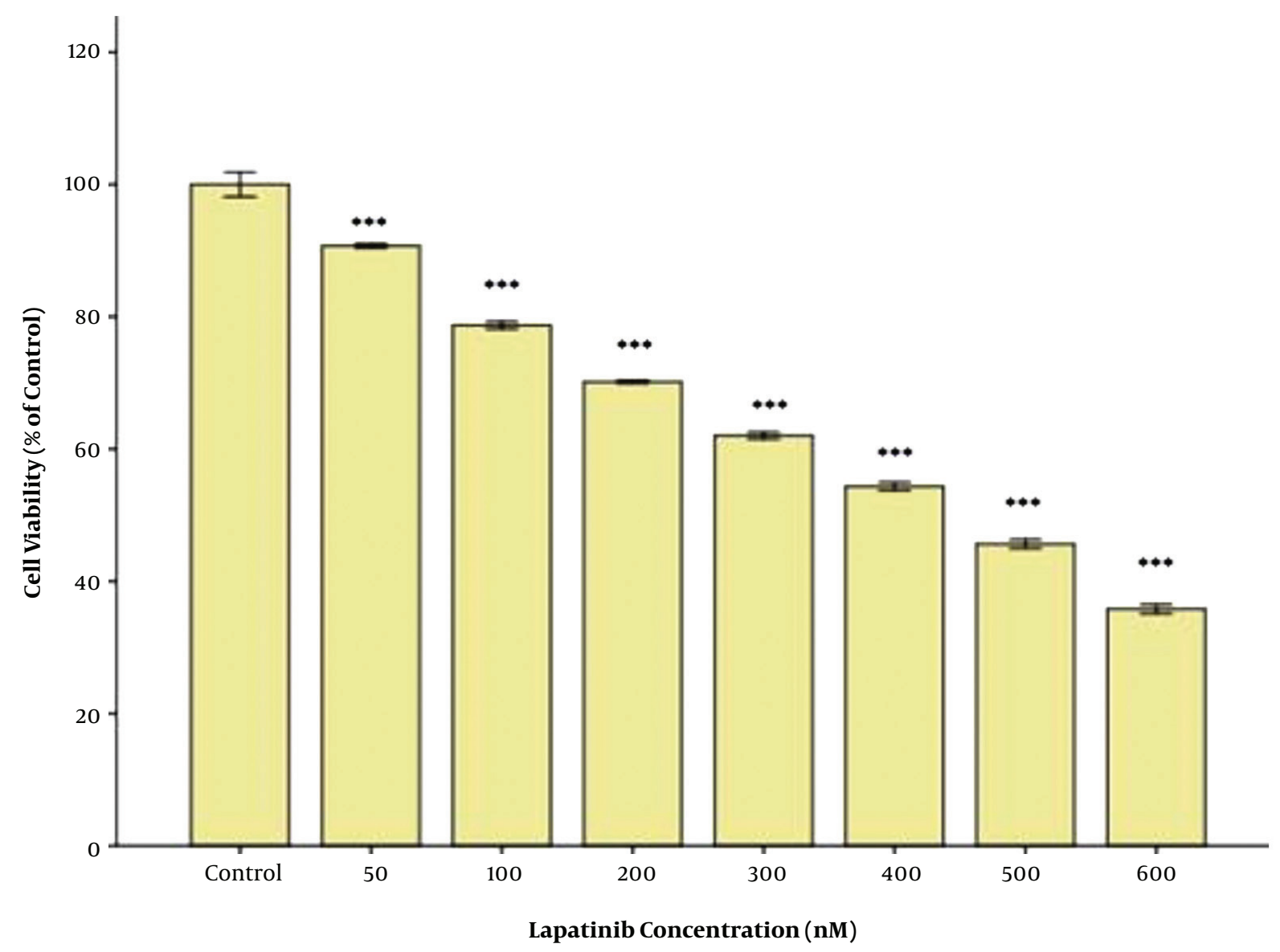

Figure 1. Cytotoxic effect of Lapatinib on the SK-BR3 cells. After treatment with various concentrations of lapatinib for $48 \mathrm{~h}$, the cells were subjected to MTT assay, and the controls remained untreated. The results are provided as mean \pm S.E.M. ${ }^{* * *} \mathrm{P}<0.001$ vs. control.

\subsection{Cytotoxic Effects of the Metformin-Lapatinib Combination on the SKBR-3 Cells}

To determine whether metformin can enhance the efficacy of the cytotoxicity effect of lapatinib against breast cancer cell lines, we assessed the inhibitory effect of the metformin-lapatinib combination on the cell viability of SKBR3 cells. As presented in Figure 3, the metforminlapatinib combination showed a higher inhibitory effect on the cell viability of SKBR3 cells compared to lapatinib used individually. A co-treatment of 20 and $40 \mathrm{mM}$ of metformin with $200 \mathrm{nM}$ of lapatinib at $48 \mathrm{~h}$ caused $40 \%$ and $50 \%$ inhibition, respectively, as compared to sole administration of lapatinib, which showed approximately 30\% inhibition. The highest inhibition (approximately 80\%) was observed in co-treatment of $40 \mathrm{nM}$ of metformin and $400 \mathrm{nM}$ of lapatinib compared to when lapatinib was used alone, which showed approximately 58\% inhibition (Figure 3).
4.3. Effect of the Metformin-Lapatinib Combination on the Bax Expression

Finally, we assessed the effect of the metforminlapatinib combination on the expression of pro-apoptotic protein Bax in SKBR-3 cells. The results indicated that when the cells were treated with $100 \mathrm{nM}$ of lapatinib alone, the expression of Bax was significantly increased in comparison to the control cells (Figures $4 \mathrm{~A}$ and $\mathrm{B}$ ). Also, the results showed that when the cells were co-treated with $10 \mathrm{mM}$ of metformin plus $200 \mathrm{nM}$ of lapatinib the expression of Bax was significantly increased in comparison to the cells that were treated with $200 \mathrm{nM}$ of lapatinib alone (Figure 4A).

\section{Discussion}

Nearly 25 to $30 \%$ of breast cancer patients experience overexpression of the human epidermal growth factor receptor gene (HER2), and its encoded protein presents in 


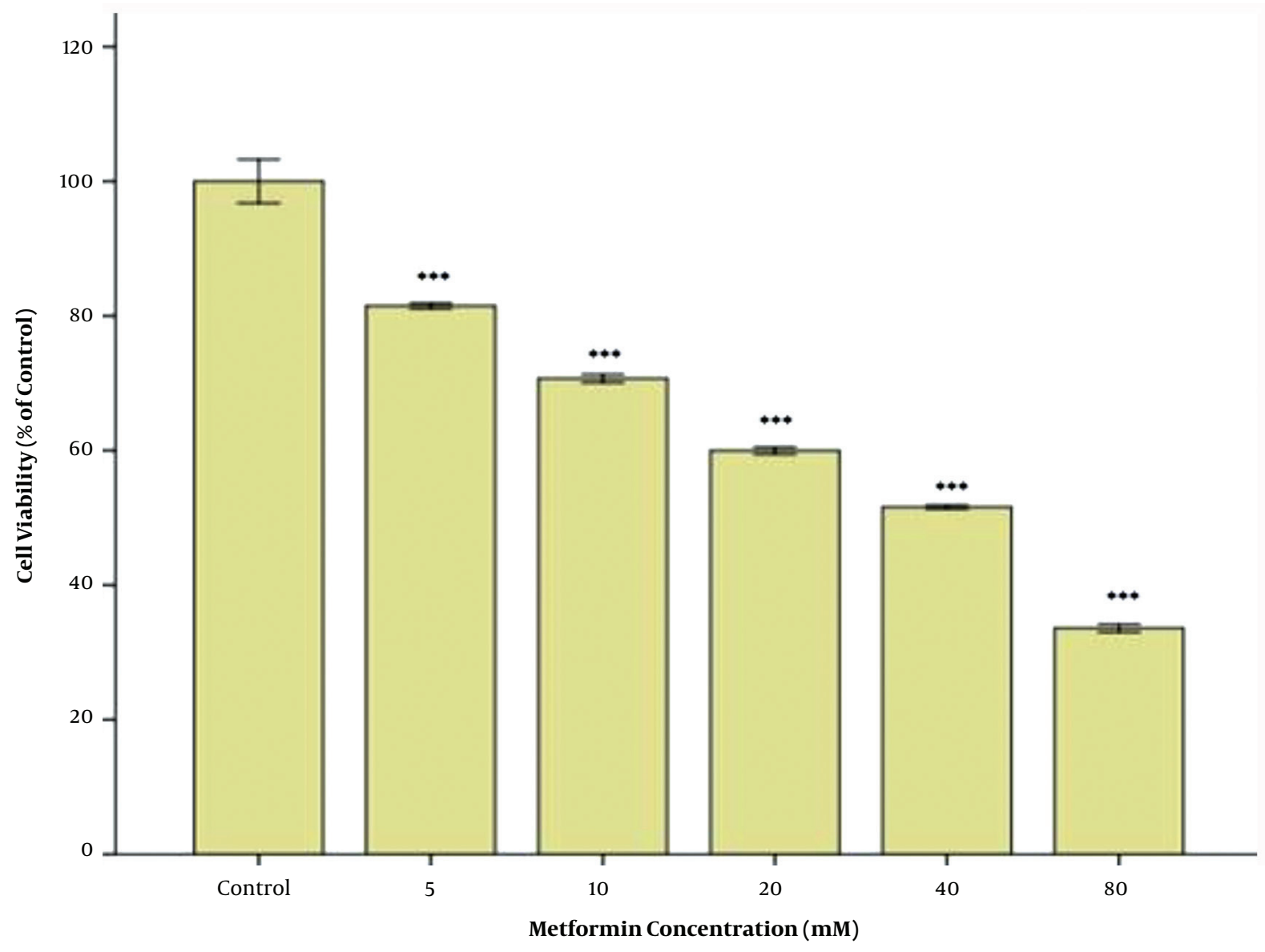

Figure 2. Cytotoxic effect of Metformin on the SK-BR3 cells. After treatment with various concentrations of metformin for $48 \mathrm{~h}$, the cells were subjected to MTT assay, and the controls remained untreated. The results are provided as mean \pm S.E.M. ${ }^{* * *} \mathrm{P}<0.001$ vs. control.

the malignant cells. Those with overexpressed HER2 experience severe forms of breast cancer with reduced diseasefree survival $(3,23)$. Various treatments are currently available for breast cancer patients, among which chemotherapy has the most severe side effects on patients' quality of life (24). Hence, developing a novel therapeutic option with lower side effects is of crucial importance. Lapatinib is widely prescribing for breast cancer patients with overexpressed HER2. However, caution should be taken when prescribing lapatinib for breast cancer patients who receive chemotherapy, particularly regarding safety measures in the qualification for treatment and identification of potential complications are necessary. Heart failure and cardiotoxicity are the most common side effects of lapatinib treatment, which are associated with decreased left ventricular ejection fraction (LVEF)(25). Some studies mentioned metformin, an anti-diabetic drug that helps to prevent cancer progression, as a safe drug (16). Moreover, we reported that co-treatment of SK-BR3 cells with combined lapatinib-metformin showed a more potent cytotoxic effect than sole treatment with each drug. After treatment with $500 \mathrm{nM}$ of lapatinib for 48 hours, the cell viability of SK-BR3 was reduced by approximately $50 \%$. While the viability was reduced approximately to 50\% after administering $200 \mathrm{nM}$ of lapatinib in combination with 40 $\mathrm{mM}$ of metformin after 48 hours. As reported by VazquezMartin et al., metformin can both stimulate AMP-activated kinase (AMPK) and reverse lapatinib resistance in MCF7/HER2 LapR cells. A $2.5 \mathrm{mM}$ concentration of metformin increased the sensitivity of MCF-7/HER2 LapR cells to lapatinib by twofold, while a concentration of $10 \mathrm{mM}$ decreased lapatinib IC50 (26).

Previous studies reported significant reductions in breast cancer progression after administering metformin in animal models with overexpression of $\operatorname{HER} 2(27,28)$. It's well-documented that metformin can promote cell 


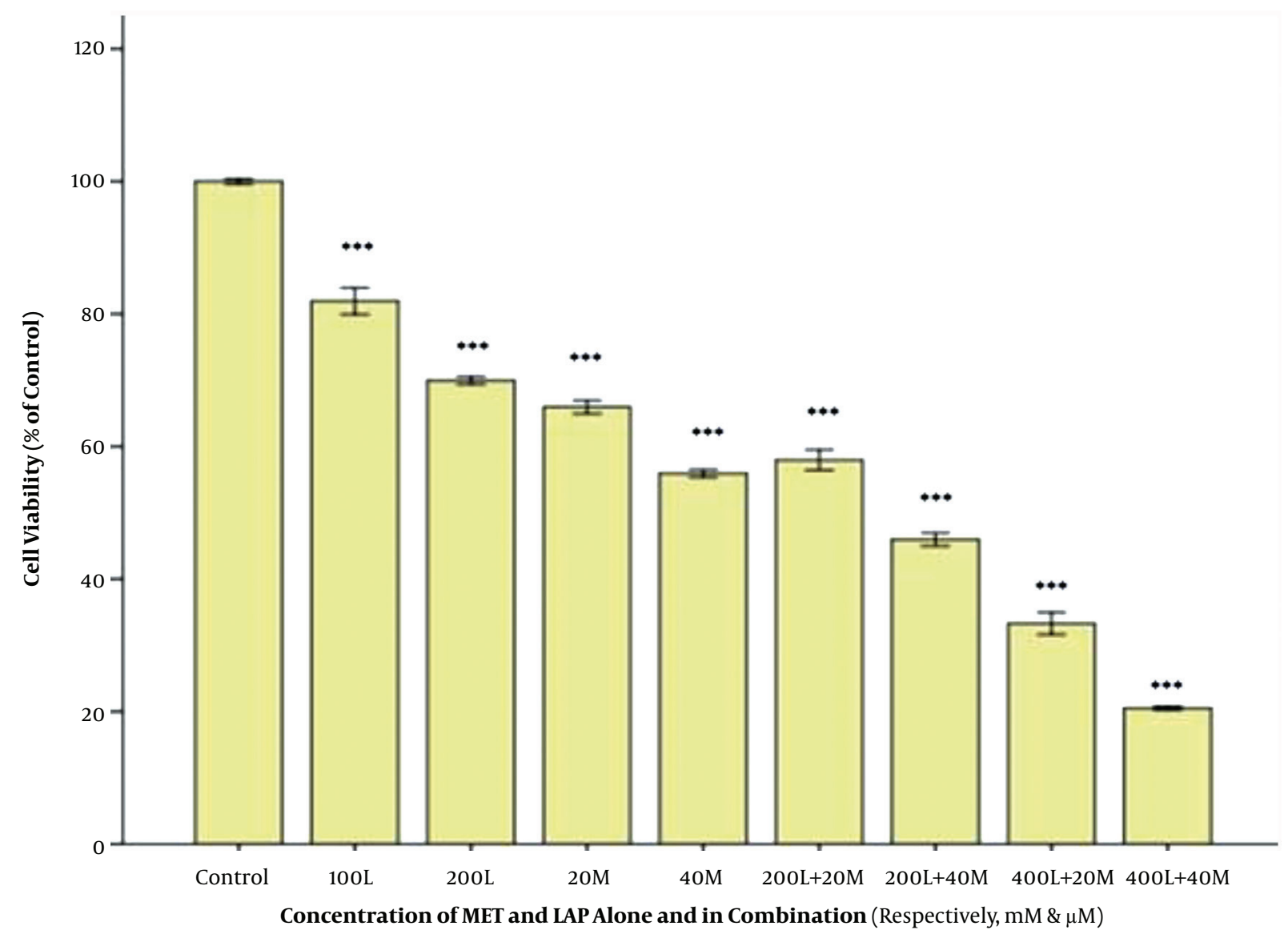

Figure 3. The cytotoxic effect of the Metformin-lapatinib combination on the SK-BR3 cells. After treatment with various concentrations of metformin-lapatinib combination for $48 \mathrm{~h}$, the cells were subjected to MTT assay, and the controls remained untreated. The results are provided as mean \pm S.E.M. ${ }^{* * * P}<0.001$ vs. control. $\mathrm{L}=$ lapatinib, $\mathrm{M}=$ metformin

cycle arrest in the G1 phase and induces apoptosis in a wide variety of breast cancer cell lines (29). According to Hangjun Gong et al., metformin selectively induced apoptosis in human gastric cancer cells but did not affect the non-cancerous cells (30). The results of the present study showed that in the SKBR-3 breast cancer cell line, metformin at $20 \mathrm{mM}$ combined with lapatinib could significantly increase the levels of pro-apoptotic Bax compared to lapatinib alone. Therefore, metformin synergistically induces a lapatinib-mediated cytotoxic effect on cell death and apoptosis. Bax, a pro-apoptotic protein of the BCL2 family, can interact with and enhances the opening of the mitochondrial voltage-dependent anion channel, which led to changes in the mitochondrial membrane permeability and release of cytochrome C. The expression of Bax is commonly regulated by the tumor suppressor P53 and may be involved in the P53 mediated cell apoptosis (31). Li $\mathrm{P}$ et al. reported that treatment of MCF-7 cells with met- formin increased the level of p53 protein and its targets, including Bax and p21. Also, metformin plays an important role in regulating P53 through AMPK-mTOR signaling. AMP-activated protein kinase (AMPK) activation, a key cellular energy sensor kinase, leads to decreased mTOR signaling, progression, and proliferation (32). Alex J Eustace et al. showed that the changes in the members of the Bcl-2 family, especially Bax, may have a key role in resistance to lapatinib, which occurs in positive HER2 tumors (33).

\subsection{Conclusion}

This study demonstrated that the metformin-lapatinib combination could synergistically inhibit the cell viability of SKBR3 cells. These in-vitro cytotoxic effects of metformin and lapatinib alone and in combination, may be mediated by increasing the level of pro-apoptotic BAX protein expression. These results confirm the possible advantage of metformin-lapatinib combination for intervention 
A

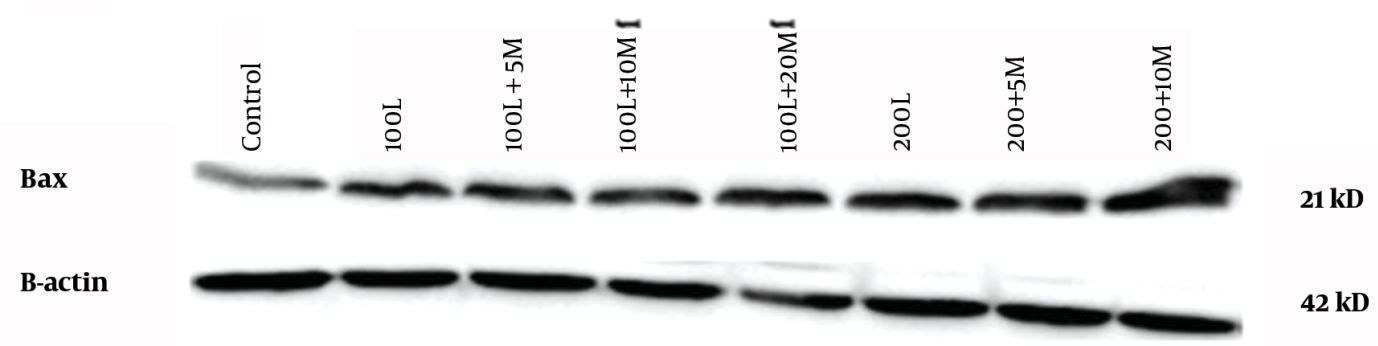

B

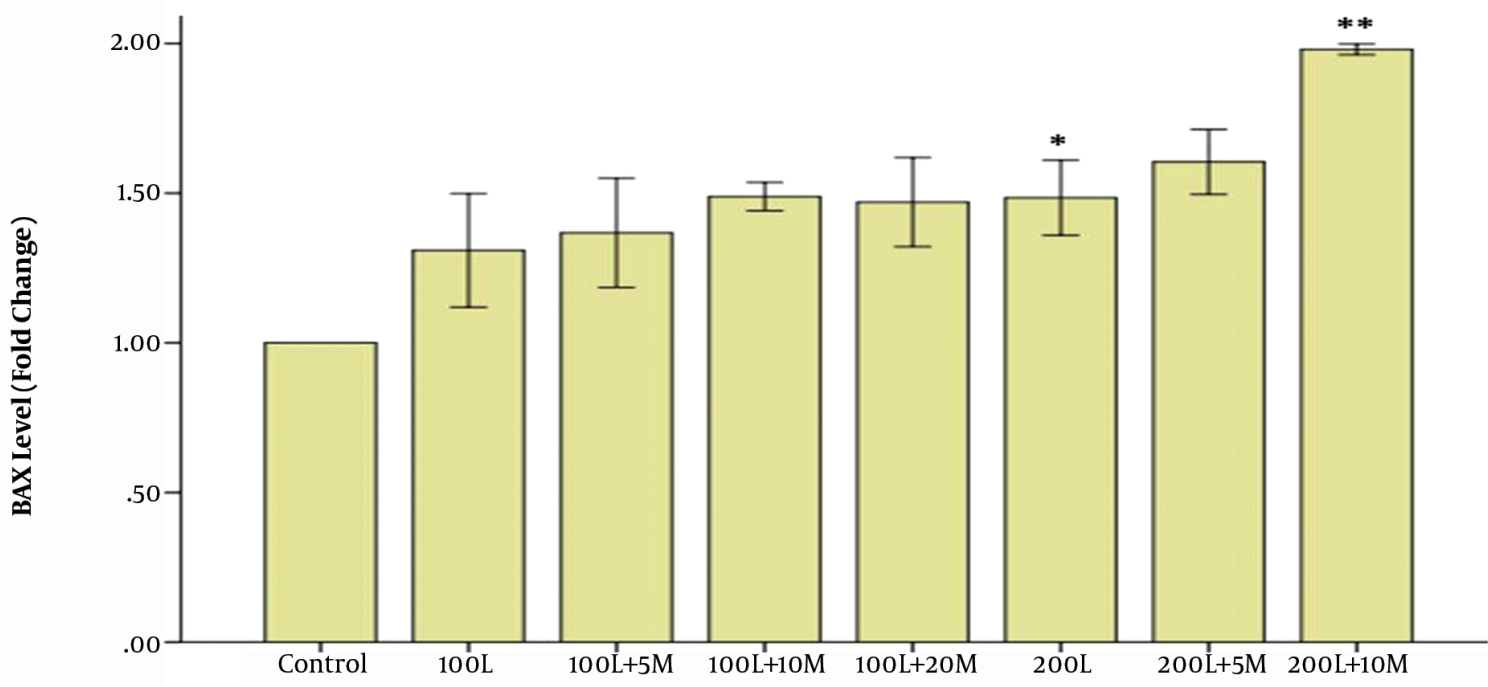

Figure 4. Effect of Metformin-lapatinib combination on the expression of Bax (A). The cells were treated with 100 and $200 \mathrm{nM}$ of lapatinib alone and various concentrations of the metformin-lapatinib combination for $48 \mathrm{~h}$. In the current experiment, the concentrations of metformin were 5,10 , and $20 \mathrm{mM}$, respectively. Image j software was used to determine the levels of Bax after Western blotting (B). $\mathrm{L}=$ Lapatinib; $\mathrm{M}=$ Metformin. The results are provided as the mean \pm S.E.M. ${ }^{*} \mathrm{P}<0.05 \mathrm{vs}$. control; ${ }^{* *} \mathrm{P}<0.01 \mathrm{vs}$. $200 \mathrm{~L}$.

in breast cancer patients with HER2 overexpression.

\section{Acknowledgments}

This research project was financially supported by the Students Research Committee of the Ahvaz Jundishapur University of Medical Sciences, Ahvaz, Iran (grant number 97s51).

\section{Footnotes}

Authors' Contribution: Bahman Moradipoodeh and Fatemeh Ahmadpour studied the concept and designed: Ghorban Mohammadzadeh did the acquisition of data. Bahman Moradipoodeh and Fatemeh Ahmadpour and
Rahim Moradi analysis and interpretation of data. Drafting of the manuscript did by Fatemeh Ahmadpour and Ghorban Mohammadzadeh. Davood Neamati, Mahdieh Koushki, and Anise Kiashi did a Critical revision of the manuscript for important intellectual content and with Rahim Moradi did a Statistical analysis. Bahman Moradipoodeh and Fatemeh Ahmadpour and Rahim Moradi did Administrative, technical, and material support.

Conflict of Interests: The authors declare no conflict of interest.

Ethical Approval: The current study is approved by the Ethics Committee of the Ahvaz Jundishapur University of Medical Sciences, Ahvaz, Iran (IR.AJUMS.REC.1397.916), (grant number 97s51). 
Funding/Support: This research project was financially supported by the Student Research Committee at Ahvaz Jundishapur University of Medical Sciences, Ahvaz, Iran (grant number 97s51).

\section{References}

1. de Martel C, Ferlay J, Franceschi S, Vignat J, Bray F, Forman D, et al. Global burden of cancers attributable to infections in 2008: a review and synthetic analysis. Lancet Oncol. 2012;13(6):607-15. doi: 10.1016/s1470-2045(12)70137-7.

2. Ferlay J, Soerjomataram I, Dikshit R, Eser S, Mathers C, Rebelo M, et al. Cancer incidence and mortality worldwide: sources, methods and major patterns in GLOBOCAN 2012. Int J Cancer. 2015;136(5):E359-86. doi: 10.1002/ijc.29210. [PubMed: 25220842].

3. Slamon DJ, Clark GM, Wong SG, Levin WJ, Ullrich A, McGuire WL. Human breast cancer: correlation of relapse and survival with amplification of the HER-2/neu oncogene. Science. 1987;235(4785):177-82. doi: 10.1126/science.3798106. [PubMed: 3798106].

4. Scheuer W, Friess T, Burtscher H, Bossenmaier B, Endl J, Hasmann M. Strongly enhanced antitumor activity of trastuzumab and pertuzumab combination treatment on HER2-positive human xenograft tumor models. Cancer Res. 2009;69(24):9330-6. doi: 10.1158/00085472.CAN-08-4597. [PubMed: 19934333].

5. Giuliano M, Hu H, Wang YC, Fu X, Nardone A, Herrera S, et al. Upregulation of ER Signaling as an Adaptive Mechanism of Cell Survival in HER2-Positive Breast Tumors Treated with Anti-HER2 Therapy. Clin Cancer Res. 2015;21(17):3995-4003. doi: 10.1158/1078-0432.CCR-14-2728. [PubMed: 26015514]. [PubMed Central: PMC4558260].

6. Yasui Y, Kim M, Tanaka T. PPAR Ligands for Cancer Chemoprevention. PPAR Res. 2008;2008:548919. doi: 10.1155/2008/548919. [PubMed: 18483618]. [PubMed Central: PMC2377329].

7. Frenzel A, Grespi F, Chmelewskij W, Villunger A. Bcl2 family proteins in carcinogenesis and the treatment of cancer. Apoptosis. 2009;14(4):584-96. doi: 10.1007/s10495-008-0300-z. [PubMed: 19156528]. [PubMed Central: PMC3272401].

8. Yip KW, Reed JC. Bcl-2 family proteins and cancer. Oncogene. 2008;27(50):6398-406. doi: 10.1038/onc.2008.307. [PubMed: 18955968].

9. Wang F, Dohogne Z, Yang J, Liu Y, Soibam B. Predictors of breast cancer cell types and their prognostic power in breast cancer patients. BMC Genomics. 2018;19(1):137. doi: 10.1186/s12864-018-4527-y. [PubMed: 29433432]. [PubMed Central: PMC5809864].

10. Callahan R, Hurvitz S. Human epidermal growth factor receptor2-positive breast cancer: Current management of early, advanced, and recurrent disease. Curr Opin Obstet Gynecol. 2011;23(1):37-43. doi: 10.1097/gco.0b013e3283414e87. [PubMed: 21500375]. [PubMed Central: PMC4307801].

11. Rusnak DW, Affleck K, Cockerill SG, Stubberfield C, Harris R, Page M, et al. The characterization of novel, dual ErbB-2/EGFR, tyrosine kinase inhibitors: potential therapy for cancer. Cancer Res. 2001;61(19):7196203.

12. Medina PJ, Goodin S. Lapatinib: a dual inhibitor of human epidermal growth factor receptor tyrosine kinases. Clin Ther. 2008;30(8):1426-47. doi: 10.1016/j.clinthera.2008.08.008. [PubMed:18803986].

13. Liu L, Liu B, Zhao Y, Chen M, Yao S, Li L, et al. Mechanism underlying inhibition of proliferation and promotion of apoptosis by lapatinib in HL60 cells. Xi Bao Yu Fen Zi Mian Yi Xue Za Zhi. 2017;33(10):1341-7.

14. Wang YC, Morrison G, Gillihan R, Guo J, Ward RM, Fu X, et al. Different mechanisms for resistance to trastuzumab versus lapatinib in HER2positive breast cancers-role of estrogen receptor and HER2 reactivation. Breast Cancer Res. 2011;13(6):R121. doi: 10.1186/bcr3067. [PubMed: 22123186]. [PubMed Central: PMC3326563].
15. Inzucchi SE, Majumdar SK. Current Therapies for the Medical Management of Diabetes. Obstet Gynecol. 2016;127(4):780-94. doi: 10.1097/AOG.0000000000001332. [PubMed: 26959197].

16. Malek M, Aghili R, Emami Z, Khamseh ME. Risk of cancer in diabetes: the effect of metformin. ISRN Endocrinol. 2013;2013:636927. doi: 10.1155/2013/636927. [PubMed: 24224094]. [PubMed Central: PMC3800579].

17. Marinello PC, da Silva TN, Panis C, Neves AF, Machado KL, Borges $\mathrm{FH}$, et al. Mechanism of metformin action in MCF-7 and MDA-MB231 human breast cancer cells involves oxidative stress generation, DNA damage, and transforming growth factor beta1 induction. $\mathrm{Tu}$ mour Biol. 2016;37(4):5337-46. doi: 10.1007/s13277-015-4395-x. [PubMed: 26561471].

18. Queiroz EA, Puukila S, Eichler R, Sampaio SC, Forsyth HL, Lees SJ, et al. Metformin induces apoptosis and cell cycle arrest mediated by oxidative stress, AMPK and FOXO3a in MCF-7 breast cancer cells. PLoS One. 2014;9(5). e98207. doi: 10.1371/journal.pone.0098207. [PubMed: 24858012]. [PubMed Central: PMC4032293].

19. Junttila TT, Li G, Parsons K, Phillips GL, Sliwkowski MX. TrastuzumabDM1 (T-DM1) retains all the mechanisms of action of trastuzumab and efficiently inhibits growth of lapatinib insensitive breast cancer. Breast Cancer Res Treat. 2011;128(2):347-56. doi: 10.1007/s10549-0101090-x. [PubMed: 20730488].

20. Vazquez-Martin A, Oliveras-Ferraros C, Del Barco S, Martin-Castillo $B$, Menendez JA. The anti-diabetic drug metformin suppresses selfrenewal and proliferation of trastuzumab-resistant tumor-initiating breast cancer stem cells. Breast Cancer Res Treat. 2011;126(2):355-64. doi: 10.1007/s10549-010-0924-x. [PubMed: 20458531].

21. Falah RR, Talib WH, Shbailat SJ. Combination of metformin and curcumin targets breast cancer in mice by angiogenesis inhibition, immune system modulation and induction of p53 independent apoptosis. Ther Adv Med Oncol. 2017;9(4):235-52. doi: 10.1177/1758834016687482. [PubMed: 28491145]. [PubMed Central: PMC5405996].

22. Chintalaramulu N, Vadivelu R, Nguyen NT, Cock IE. Lapatinib inhibits doxorubicin induced migration of HER2-positive breast cancer cells. Inflammopharmacology. 2020;28(5):1375-86. doi: 10.1007/s10787-02000711-9. [PubMed: 32378049].

23. Slamon DJ, Godolphin W, Jones LA, Holt JA, Wong SG, Keith DE, et al. Studies of the HER-2/neu proto-oncogene in human breast and ovarian cancer. Science. 1989;244(4905):707-12. doi: 10.1126/science.2470152. [PubMed: 2470152].

24. Vanneman M, Dranoff G. Combining immunotherapy and targeted therapies in cancer treatment. Nat Rev Cancer. 2012;12(4):23751. doi: 10.1038/nrc3237. [PubMed: 22437869]. [PubMed Central: PMC3967236].

25. Seidman A, Hudis C, Pierri MK, Shak S, Paton V, Ashby M, et al. Cardiac dysfunction in the trastuzumab clinical trials experience. J Clin Oncol. 2002;20(5):1215-21. doi: 10.1200/JCO.2002.20.5.1215. [PubMed: 11870163].

26. Vazquez-Martin A, Oliveras-Ferraros C, del Barco S, Martin-Castillo B, Menendez JA. The antidiabetic drug metformin: a pharmaceutical AMPK activator to overcome breast cancer resistance to HER2 inhibitors while decreasing risk of cardiomyopathy. Ann Oncol. 2009;20(3):592-5. doi: 10.1093/annonc/mdn758. [PubMed: 19153119].

27. Anisimov VN, Berstein LM, Egormin PA, Piskunova TS, Popovich IG, Zabezhinski MA, et al. Effect of metformin on life span and on the development of spontaneous mammary tumors in HER2/neu transgenic mice. Exp Gerontol. 2005;40(8-9):685-93. doi: 10.1016/j.exger.2005.07.007. [PubMed: 16125352].

28. Anisimov VN, Egormin PA, Bershtein LM, Zabezhinskii MA, Piskunova TS, Popovich IG, et al. Metformin decelerates aging and development of mammary tumors in HER-2/neu transgenic mice. Bull Exp Biol Med. 2005;139(6):721-3. doi: 10.1007/s10517-005-0389-9. [PubMed: 16224592]. 
29. Grossmann ME, Yang DQ, Guo Z, Potter DA, Cleary MP. Metformin Treatment for the Prevention and/or Treatment of Breast/Mammary Tumorigenesis. Curr Pharmacol Rep. 2015;1(5):31223. doi: 10.1007/s40495-015-0032-z. [PubMed: 26405648]. [PubMed Central: PMC4577062].

30. Han G, Gong H, Wang Y, Guo S, Liu K. AMPK/mTOR-mediated inhibition of survivin partly contributes to metformin-induced apoptosis in human gastric cancer cell. Cancer Biol Ther. 2015;16(1):77-87. doi: 10.4161/15384047.2014.987021. [PubMed: 25456211]. [PubMed Central: PMC4622954].

31. Brunelle JK, Letai A. Control of mitochondrial apoptosis by the
Bcl-2 family. J Cell Sci. 2009;122(Pt 4):437-41. doi: 10.1242/jcs.031682. [PubMed: 19193868]. [PubMed Central: PMC2714431].

32. Li P, Zhao M, Parris AB, Feng X, Yang X. p53 is required for metformin induced growth inhibition, senescence and apoptosis in breast cancer cells. Biochem Biophys Res Commun. 2015;464(4):1267-74. doi: 10.1016/j.bbrc.2015.07.117. [PubMed: 26225749].

33. Eustace AJ, Conlon NT, McDermott MSJ, Browne BC, O'Leary P, Holmes FA, et al. Development of acquired resistance to lapatinib may sensitise HER2-positive breast cancer cells to apoptosis induction by obatoclax and TRAIL. BMC Cancer. 2018;18(1):965. doi: 10.1186/s12885-0184852-1. [PubMed: 30305055]. [PubMed Central: PMC6180577]. 